TI 2002-033/3

Tinbergen Institute Discussion Paper

Measuring and Explaining the

Limited Take-Up of the Housing

Benefit in the Netherlands

Jan Rouwendal

Department of Social Sciences, Wageningen University,

Department of Spatial Economics, Faculty of Economics and Business Programming, Vrije Universiteit Amsterdam, and

Tinbergen Institute 
Tinbergen Institute

The Tinbergen Institute is the institute for economic research of the Erasmus Universiteit Rotterdam, Universiteit van Amsterdam and

Vrije Universiteit Amsterdam.

Tinbergen I nstitute Amsterdam

Keizersgracht 482

1017 EG Amsterdam

The Netherlands

Tel.: +31.(0)20.5513500

Fax: $\quad+31 .(0) 20.5513555$

Tinbergen Institute Rotterdam

Burg. Oudlaan 50

3062 PA Rotterdam

The Netherlands

Tel.: $\quad+31 .(0) 10.4088900$

Fax: $\quad+31 .(0) 10.4089031$

Most TI discussion papers can be downloaded at

http://www.tinbergen.nl 


\title{
Measuring and Explaining the Limited Take-Up of the Housing Benefit in the Netherlands
}

\author{
Jan Rouwendal \\ Department of Social Sciences, Wageningen University \\ Department of Spatial Economics, Free University \\ Tinbergen Institute
}

This version: March 14, 2002

JEL-codes: H53, I38, H23, C81.

Keywords: housing benefit, means-tested benefits, non-take-up.

\begin{abstract}
It is well known that the take-up rate of the Dutch housing benefit and other means tested benefits is substantially below $100 \%$. In order to measure non-take up one usually has to simulate entitlement to the benefits. In this paper we take a closer look at the quality of the simulation. We find evidence that simulation error is much more important than has often been assumed in earlier studies. These studies use the simulation of entitlement in order to select the sample on which an explanatory model for the take-up decision is based. Simulation error may therefore lead to biases in the explanatory analysis. Our analysis suggests that a discrepancy between the income that is reported in our database and the income on which the decision to apply for the benefit is based is an important source of simulation error.

The data that were available for this study contain information about refused applications and therefore allow us to estimate a richer model than is conventionally used for the analysis of take-up rates. In this model both the decision of a renting household to apply for the benefit and that of the authorities to grant or refuse the subsidy are analyzed. Estimation results for this model differ from that of the first.

A third model is explicitly based on the assumption that the decision-making processes are based on an income level that may be different from that reported in the data. For households that receive the housing benefit we can compute this alternative income. This third model can be estimated if it is assumed that the same joint distribution of the two incomes is relevant for households who did not apply for the benefit. Estimation results for this model are again different from those of the other two. They suggest that measurement error in rent, received benefits or housing composition are also more important that has been thought.
\end{abstract}

\section{Acknowledgement}

The author thanks Willem Relou and Rinke Karman of the Dutch Ministry of Housing, Spatial Planning and the Environment for providing information about the IHS. The usual disclaimer applies. 


\section{Introduction}

It is well known that the take up of benefits for which entitled persons have to apply is considerably less than $100 \%$, even in situations where it is easy to claim the benefit and the possible negative effects of doing so appear to be small. Non-take is especially problematic when the benefits are intended to relieve problems associated with low incomes. Entitlement to such benefits is usually dependent on income and household characteristics and claiming the subsidy therefore requires that information about these variables is provided to the administrative unit involved in the execution of the benefit measure. Studies have often found that take up is as low as 60 or $70 \%$ (see, for instance, Moffit (1983), Blundell, Fry and Walker (1988), Koning and Ridder (1997) Daponte et al (1998), Gibson (2001) and Alessie, Hochguertel and van Soest (2001)).

In many countries there is a means-tested benefit associated with the housing market, which is directed especially towards people with low incomes and a high rent to income ratio. This benefit is often also an important instrument of relieving the problems associated with poverty. For this reason, there is a special interest in the non-take-up of these benefits. In order to assess this phenomenon it is necessary to measure the take-up correctly and analyze its causes. Problems are associated with both tasks. In order to measure non-take-up, the researcher has to simulate the entitlement of households to the benefit, usually on the basis of incomplete and noisy information contained in a survey. A severe problem is that the information contained in such a survey is different from that used in granting or refusing the subsidy. If the survey is held in year $t$, the benefit received by households in that year is reported, as well as income, rent, household composition et cetera. However, the benefit received in year $t$ is often based on an application from year $t-1$, and income may have changed since then. This problem is addressed in the literature (see e.g. the discussion in Blundell, Fry and Walker (1988)), but is hard to overcome. If entitlement is simulated incorrectly, the resulting figures about non-take-up are of course also incorrect. Moreover, explanatory analysis of the reasons for non take-up might easily lead to biased results.

This paper analyzes the non-take-up of the Dutch housing benefit, and special attention will be paid to problems associated with measuring non-take-up. Changes and reporting errors in income are identified as the most important source of errors in the simulation of entitlement. Information about refused claims and differences between simulated and received benefits is used in order to evaluate and improve upon conventional estimates of non-take-up. Moreover, models are estimated that link the take up and granting decisions to explanatory variables at the household level. The paper is organized as follows. In section 2 we give a brief introduction to the Dutch housing benefit and the Dutch housing needs survey that will be used in the empirical work. We discuss the simulation procedure and the errors to which it is prone. In section 3 we present information on the take-up of the housing benefit that results from our simulation and interpret it in the light of our discussion about simulation errors. Section 4 briefly reviews some relevant literature and continues with a description of the models used in this paper. Section 5 gives estimation results. Section 6 concludes.

\section{The Dutch housing benefit and housing needs survey}

The Dutch housing subsidy was introduced in the early seventies. The situation on the Dutch housing market in that period was characterized by rent control, relatively large 
population growth, limited supply of new housing and severe excess demand. This implied that households who had to move or to find a rental house for the first time had little choice. They were virtually forced to accept the first dwelling offered to them, even if this implied that rent would be a very large share of their income. Refusal would imply the postponement of a move or of household formation for an indefinite period. As a consequence, houses with high rents were accepted by households with low incomes. The main purpose of the subsidy was to relieve the problems this caused by giving financial aid to households with relatively low incomes and a high share of housing expenditure. The subsidy was called in Dutch Individuele Huur Subsidie (= individual rent benefit). It will be often referred to below by its abbreviation in Dutch: IHS.

In the mid-seventies the IHS came to be regarded by the left wing coalition then in government as a providing an important possibility for increasing the choice set of low-income households on the housing market. The conditions for entitlement were relaxed considerably and the amount of benefit that could be received was increased. During the eighties the political support for subsidized construction of housing, that used to be the main instrument of Dutch housing policy, disappeared. Generic subsidies on housing construction were abolished in the early nineties and the housing benefit became the dominant instrument of Dutch housing policy.

The IHS is a means tested form of state support, which is directed explicitly at low income households. The benefit is therefore also an important element of Dutch poverty policy. In this context the question of the non take-up of this subsidy received special significance and a number of studies have been published that conclude that a large share of the Dutch households that are entitled to the IHS do not receive it (see Conijn and Lamain (1992), Vrooman and Asselberghs (1994), van Oorschot (1994), Wildeboer Schut (1997), Koning and Ridder (1997), Rouwendal (2000)). A large share (approximately 40\%) of the target group is not reached by the subsidy. This suggests that the policies concerned with housing the poor can hardly be regarded as successful.

In the next section we take a closer look at the way most of these studies have dealt with the measurement error in simulating the entitlement of households to the benefit. Before being able to do so, we first have to take a closer look at the details of the benefit and the data that inform us about its take up.

\section{Details about the Dutch housing benefit (IHS)}

The basic idea of the IHS is that households are able to spend a certain share of their income on housing without being in need of government assistance. This share is increasing in income. Only those households that spend a larger share of their income on housing have to be subsidized. This idea corresponds closely to the original motivation for the benefit, viz. to relieve the problems associated with severe excess demand for low income households.

Accordingly, the amount of money to be received by a household entitled to the IHS is in principle equal to the difference between the actual rent paid and the rent the household should be able to pay itself. The latter is called the normhuur, the normative rent. The government does not always pay the complete difference: when the rent is higher than a certain threshold, only a part of the difference is paid. The motivation for the implied reduction in the subsidy is that the household also enjoys the usually higher quality of the more expensive house. What follows is a more detailed description of the measure. 
In order to take into account the differences in need associated with household circumstances, four groups of households are distinguished on the basis of the number of persons and the age of the person with the highest income. Groups 1 and 3 are one person households with age less than or at least equal to 66, respectively. Groups 2 and 4 are households with at least two persons, where the person with the largest income has age less than or at least equal to 66, respectively. Entitlement is only possible if income and rent do not exceed group specific maximum levels. Moreover, household wealth should not exceed a critical level, which is also group specific. The rent a household should be able to pay without needing a supplementary benefit is defined as a fraction of taxable household income as defined in the administrative rules for IHS. We refer to this income as IHS-income. IHS-income is the sum of the taxable incomes of all the persons in the households. Taxable income of adult earners is in principle equal to the taxable income as defined by the income tax authorities in the Netherlands and can therefore be verified. However, tax authorities do not know the household's current income. The most recent information they have concerns household income in the calendar year preceding the application for IHS. In order to enable verification, the government has therefore decided that applications for IHS should be based on taxable income in the year preceding the application. Exceptions can be made for households whose income has changed. If there are children in the household with their own income, this has to be included in the household income if it exceeds Dfl 9000,-.

The basic rule is that the normative rent, the normhuur, is a fraction of income that increases linearly with income. If we denote the normative rent as $n h$ we have:

$$
\frac{n h}{y^{i h s}}=a_{i}+b_{i} y^{i h s} \quad i=1 . .4
$$

In this equation $y^{\text {ihs }}$ denotes the income that is used in determining a household's entitlement for the housing benefit, i.e. the household's IHS-income. $a$ and the $b$ are group-specific coefficients. The basic rule is amended by the following additional rules:

- if IHS-income is below a group-specific minimum level, the normative rent is always equal to Dfl 330,- per month,

- if IHS-income is above a group-specific maximum level, the household is never entitled to the housing benefit and the normative rent is undefined,

- the administrative procedure uses tables for IHS-incomes and normative rents that define a single normative rent for yearly incomes in intervals of Dfl 500,- and Dfl 1000 ,- (the latter for higher income levels); this effectively transforms the above equation into a step function

The above equation implies that the normative rent $n h$ is basically a quadratic function of IHS-income, with $b$ the coefficient for income squared. This reflects the desire to focus the benefit system on low-income groups, but has the unfortunate consequence that increases in income imply more than proportional decreases in the housing benefit. This contributes to the existence of a poverty trap.

Once the normative rent has been determined, the value of the benefit follows from a comparison between actual rent and normative rent. ${ }^{1}$ Actual rent is the rent the

\footnotetext{
${ }^{1}$ The owner of the house has to announce the intended increase of the rent during the first half of the calendar year. Rents are increased by July 1 and remain constant until June 30 of the next year. Rent
} 
household has to pay at the moment the application is made, with the rent increase announced by the owner of the house added to it. A necessary condition for entitlement is that the actual rent exceeds the normative rent. The value of the benefit is determined as the sum of the following components:

i) The difference between a) the maximum of the actual rent and a threshold level $\mathrm{A}$ and $\mathrm{b}$ ) the normative rent. If the normative rent is higher than $\mathrm{A}$, this component is equal to 0 .

ii) $75 \%$ of the difference between a) the maximum of the actual rent and a second threshold level $\mathrm{B}$ and $\mathrm{b}$ ) the maximum of the normative rent and $\mathrm{A}$. If the normative rent is higher than $\mathrm{B}$, this component is equal to 0 . If all persons in the household are younger than 23, this component is always equal to zero.

iii) If the household does not belong to group 2, 50\% of the difference between a) actual rent and $\mathrm{b}$ ) the second threshold level $\mathrm{B}$. If the household belongs to group 2, this component is equal to 0 .

iv) For households with children the subsidy is increased by a fixed amount per month that depends on the number of children.

In order to facilitate the administration of applications for the subsidy by the municipal authorities, he ministry provides an annual handbook. The handbook contains detailed instructions for the determination of the relevant income level and tables that relate that level to the normative rent for each of the four groups.

\section{The Dutch housing needs survey (WBO)}

Most of the research on take-up of the IHS makes use of the Dutch Woning Behoeften Onderzoek (=housing needs survey) to which we will often refer by means of its abbreviation in Dutch as WBO. The WBO is a large survey that is carried out every four years and provides information about income level, household composition, housing situation and related issues of thousands of Dutch households. In this paper we use the 1998 version of the survey which has more than 100,000 respondents. Earlier versions of the WBO were used in other research. Below a brief description is provided of the information that is relevant for the simulation of entitlement to the IHS and the implied value of the benefit. We restrict attention to renting households. WBO respondents are asked to report the rent they pay, whether they receive IHS and if so, which amount. They are also asked to report their income and if they have a partner, his or her income. Other questions refer to household composition. For the purpose of simulating a household's entitlement to IHS, it is important to note that neither rent, nor income need to be reported directly by the respondent in the same way as this should be done on an application form for IHS. Rent as reported by the respondent may include costs for heating, water and electricity as well as other services provided by the owner of the house. Rent may also be reported as what remains to be paid after the housing benefit is taken into account. ${ }^{2}$ Additional questions are included in the questionnaire in order to correct for these issues as much as possible. If a respondent indicates that rent as reported by him or her contains such elements, but does not know the exact amounts of money involved, estimates (constructed by Statistics Netherlands) are used to make corrections.

With respect to income, most respondents indicate the amount of money they receive from their employer, i.e. their net monthly income. However, this income is different

increases are subject to rent control. Rent increases that exceed a percentage indicated by the government should motivate their proposal and may not be allowed to do so.

${ }^{2}$ Sometimes this is what the households pays to the owner of the house. The housing benefit is then transferred directly to the owner of the house. 
from taxable income and it is not always straightforward to compute one from the other. The Dutch income tax system is complicated, and has special features relating, for instance, to dual earners. Additional questions are asked in order to make the computations of taxable household income reliable, but also here Statistics Netherlands makes imputations in order to arrive at the figures that are reported in the data that are made available for research such as reported in this paper.

\section{Implications for simulated entitlement for IHS}

In order to simulate a household's entitlement for IHS, one may use the information about taxable income and household composition from WBO and if income does not exceed the maximum income level for which entitlement is possible, read the implied normative rent from the table of the relevant household group. If the actual (corrected) rent reported in the WBO exceeds the normative rent, a household is entitled, provided the rent does not exceed a maximum level. A relatively simple computation reveals the value of the benefit. This is a straightforward procedure.

A complication occurs because of the timing of the data collection for WBO98. This took place during the whole year, whereas the rules according to which the IHS is determined change at July 1 . Since we are unable to identify the data at which the interview took place, we cannot be sure whether we should simulate entitlement on the basis of the rules that were used on the period July 1997-June 1998 or July 1998June 1999. We followed current practice at the Dutch ministry of housing and used the rules of 1997/8. Some simulation error is unavoidably caused by this uncertainty. However, since the changes of the rules are mainly adjustments for inflation, this error should be expected to be small.

Simulation results are of course prone to other sources of error as well. An important shortcoming of the procedure sketched above is that it does not use information about household wealth. If this variable exceeds a group-specific threshold, no subsidy can be claimed. Since the WBO contains no information about household wealth, no correction can be made.

Other obvious causes of simulation errors are changes in rent, household composition and income. In order to avoid them, attention may be restricted to households that reported not to have moved ${ }^{3}$ in the period of, say, one year preceding the WBOinterview. It is possible to do so on the basis of information contained in the WBO. Ideally, one would also exclude households who have experienced changes in income, and household composition, but here WBO does provide no information. ${ }^{4}$

Reporting errors and errors made in the estimation of components for which respondents did provide insufficient information are another source of simulation errors. One expects that, also in this respect, errors in reported income are the most important ones. In many cases households know exact what they pay for heating et cetera and there is no reporting error at all. In most other cases reliable estimates can be made on the basis of household and housing characteristics that are reported in WBO. On the other hand, the relation between reported net income of a respondent and taxable household income is not a straightforward one. It is complicated by being dependent on household specific variables that are not reported in WBO, such as the presence of other income.

\footnotetext{
${ }^{3}$ Because of rent control, households do never have to accept large changes in rent for a dwelling in which they reside.

${ }^{4}$ Earlier versions of WBO provided information about changes in the household composition prior to the interview, but the 1998 does not.
} 
Finally, we have to remember that applications for IHS are as a rule granted on the basis of information about taxable income in the year preceding the WBO-interview. If this interview took place in the first half of 1998, the subsidy received by then was granted on the basis of an application form filled in the first half of 1997, approximately a year earlier. In the application form, taxable income for 1996 had to be reported. This implies that changes in income that occurred two years before the WBO-interview might cause a discrepancy between the actual and the simulated entitlement of a household. ${ }^{5}$

The following conclusions emerge from the discussion above:

- simulations based on WBO data are unable to incorporate the wealth constraint

- simulation errors caused by recent changes in household composition or rent associated with moving house can be avoided by restricting attention to households who reported have arrived in their current house before, say, 1997.

- reporting errors in rent seem to be of minor importance

- reporting errors in income seem to be of major importance (at least in a relative sense) because (i) respondents will usually report their net income, from which it is not straightforward to deduce household income and (ii) the actual entitlement for IHS depends not on actual income, but on taxable household income in 1996 (when the WBO-interview took place before July 1, 1998).

These conclusions identify taxable household income as the main determinant of simulation errors.

\section{Deriving the relevant income level for entitlement from WBO}

Before concluding this section, we should note one other feature of the IHS and the information contained in WBO. If we have information about household composition, rent and the IHS actually received by the household, we can compute from this information the taxable household income that would have given rise to this combination of variables. The procedure is as follows. We know the rules according to which the value of the IHS is determined from the difference between actual rent and normative rent. Using these rules, we can deduce the household's normative rent from the actual rent and the housing benefit. The tables that relate the normative rent to income levels for each of the four groups relevant for IHS then allow us to determine the level of taxable income of this household.

Since the tables to be used give normative rents for household incomes in particular intervals, this procedure does not result in exact figures. However, the intervals are in all but one case relatively small: Dfl 500,- for low incomes and Dfl 1000 for higher incomes. The single exception concerns households with an income that is at or below the social minimum income relevant for this group, i.e. the income level that is regarded as the absolute minimum in the Dutch welfare state. Households usually can claim compensation up to this income level. For later reference we call the income computed in this way the IHS-income, in order to distinguish it from taxable household income as reported in WBO. We refer to the latter as WBO-income. It must be noted that this procedure assumes that the information about household characteristics, rent and IHS received is correct and that any errors in these variables

\footnotetext{
${ }^{5}$ Consider for instance, someone who has been unemployed during the first months of 1996, but then found a job. If he had been employed during the whole year 1996, he would not be entitled to IHS. However, the unemployment in the beginning of the year might leave the normative rent computed on the basis of actual total yearly below the actual one. Our simulation would indicate that this person is not entitled if he has the same income in 1998 as he had in 1996 after becoming employed, but in fact he is.
} 
lead to errors in the computed income. Moreover, it assumes that the correct rules for determining the value of the benefit from information about rent, income and household composition are used. Because of the uncertainty concerning the exact date of the interview and the limited change in these rules that occurred at July 1, 1998, this assumption is not completely valid.

\section{Measuring the take up of the housing benefit}

In this section the results of simulating the entitlement to IHS and comparing them with reported receipt of the benefit are discussed. Most of the relevant information is contained in Table 1. The simulation refers to all renting households contained in the WBO of 1998. We have left out those observations for which (i) insufficient information was provided to determine the group to which the household belongs (ii) income was not reliably reported according to the supplier of the survey ${ }^{6}$ (iii) no rent was reported. The figures in the table refer to respondents in WBO 98. Their numbers are not weighted. Because some parts of the Netherlands are over-sampled, the patterns that emerge from the table are not necessarily representative for the Netherlands as a whole.

Row 1 of Table 1 gives the total number of WBO-respondents belonging to each of the four household groups that are distinguished in the IHS rules. Group 2 is the largest of these with more than 20,000 respondents in the WBO '98 belonging to it. Earlier studies of the take-up of IHS have usually restricted attention to this group. The second row of the table gives the numbers of households that report to have arrived in their current house in 1997 and 1998. Since such moves are usually associated with changes in rent and household composition, including these observations would probably make the analysis less accurate.

The third row of table 1 shows that, according to our simulation, a considerable fraction of the remaining households in each group is entitled to IHS. One third of the singles, a quarter of the other households and about $50 \%$ of the elderly that live in a rented house should be able to apply successfully for the benefit if our simulation is accurate. Row 4 shows that many of these households actually do not receive IHS. For the households consisting of more than one person (groups 2 and 4) the non takeup is apparently more than $50 \%$. These figures are somewhat higher than those found in other studies. There are several possible reasons for this result. Over-sampling may have been concentrated in regions where take-up is lower than on average. ${ }^{7}$ For a number of the apparently entitled households an application for the benefit is still under consideration (row 6), and for others an application was refused (row 7). The ratio of (a) households with refused applications and (b) the number of apparently entitled households who do not report to have an application that is still under consideration is between 19 and $25 \%$. This indicates substantial simulation error or substantial errors in the way the benefit is granted. Of these two possibilities, the former is the most probable one. It may, moreover, be noted that some households who did not apply for the subsidy perceived the probability of being granted the benefit to be too low to make application worthwhile.

Row 5 shows the monthly value of the benefit that, according to our simulation, could have been received by the households that did not take up the benefit. This value is, for three of the four groups, lower than the average amount received by those who

\footnotetext{
${ }^{6}$ This is indicated by a variable constructed by Statistics Netherlands.

${ }^{7}$ For instance, in the larger cities private renting is more common than elsewhere in the Netherlands and renting from a private person is known to be associated with a lower take-up of the benefit (see below).
} 
have successfully applied for the benefit (row 9). This result, which is often observed in simulations of this type, is consistent with the view that non-take up is caused by (some kind of) participation costs. The benefits to be expected from claiming the subsidy should exceed the cost associated with it before a rational individual will do so. In order to assess the validity of this interpretation for the data at hand, we have listed the take up rates for some intervals of the actual (for households receiving the benefit) or simulated (for households not receiving) benefit. The results are shown in Table 2. This table shows that, except for group 3. Take-up rates do not increase with the amount of the benefit that might be claimed.

Rows 10-17 provide information about the differences between the simulated value of the benefit and that reported by the WBO-respondents. One should, of course, not expect a complete correspondence between simulation results and actual figures, due to reporting errors in income and rent. If the simulation is accurate, such errors should in general be expected to be small. However, if we interpret small to mean 'less than $5 \%$ ' in either direction, we find that for the majority of the households who receive IHS the errors are large. There seem to be especially many households that receive more than 5\% less than the amount to which they are entitled.

Earlier studies on the take-up of IHS have also noted that a large fraction of the households that receive IHS, receive considerably less than the simulated amount and attributed this to partial take up (see, for instance, Vrooman and Asselberghs (1994)). Partial take-up may be caused by reluctance of applicants to reveal their low income to their social environment by claiming the complete subsidy to which they are entitled. They might instead claim a lower subsidy in order to avoid the stigma associated with their actual low income (see Moffit, 1983). It seems likely, however, that most of the stigma associated with receiving IHS (if it exists) is associated with claiming (and possibly receiving) the subsidy at all, and is more or less independent of the amount of the benefit that can be claimed. The standard procedure for claiming IHS requires that the applicant reveals his or her income, rent and household composition. Claiming a benefit that is smaller than the one to which the applicant is entitled requires him or her to provide false information. Doing so is prohibited.

On the basis of the discussion offered in the previous section, it seems much more likely that a large part of the partial non take-up is caused by simulation error, probably associated with differences between IHS-income and WBO-income. This suggestion is supported by the existence if a large number of households for which the simulated benefit is smaller than the reported one. This feature of the data cannot be explained by a desire to avoid stigma. However, simulation error offers a convincing explanation. $^{8}$

Note also that, apart from stigma and simulation error, no other explanation for (complete) non take-up seems to be able to explain partial non-take-up as well. Partial non-take-up cannot be explained in terms of lack of knowledge, stigma or problems associated with filling forms. The simple reason is that households that (supposedly) under-utilize their entitlement to IHS must have requested the subsidy. ${ }^{9}$

\footnotetext{
${ }^{8}$ It may also be noted that a symmetric simulation error in income gives rise to a-symmetric errors in the amount of the benefit. If WBO-income is lower than IHS-income, this will always lead to a simulated benefit that exceeds the actual benefit. However, if WBO-income is higher than IHS-income the simulated subsidy is too low, or the simulation suggests that the household is not entitled. The quadratic relation between the normative rent and income increases this asymmetry.

${ }^{9}$ An alternative explanation for the over-utilization of IHS (simulated benefits is smaller than reported benefit) is, of course, fraud. However, it seems unlikely that this would exist on such a large scale and would be reflected in the figures reported in WBO to such an extent.
} 
The last five rows of the Table inform us about the households that are, according to our simulation, not entitled to IHS. The large majority of these households do not receive the benefit. Between 10 and 20\% of these non-receivers had applied for the benefit, but were not granted it. Some $10 \%$ of those not entitled (but a lower fraction of the large group 2) do receive IHS. The average amount received is smaller than that for the entitled receivers.

The analysis presented above strongly suggests that simulation error should play a much larger role in the explanation of figures like those presented in Table 1 than was usually recognized in earlier Dutch research on non-take-up of the housing benefit. The main reasons for drawing this conclusion are the information about refused claims (which was not available in earlier versions of WBO) and the fact that a substantial number of households received a larger benefit than was suggested by our simulation. The latter fact could have been observed earlier (see Rouwendal, 2000). Simulation error leads to bias in the conclusions about non-take-up if it is not recognized. Moreover, if an explanatory analysis of the simulated non-take-up is given, its results will be biased as well. This issue will be discussed further in the next section.

Some of the results reported above for the Dutch IHS are also found in other studies. In order to illustrate this we make a comparison with Blundell, Fry and Walker (1988). They analyze the take-up of the housing subsidy in the United Kingdom by simulating the entitlement to the subsidy and comparing their simulation results with reported receipts. The authors pay considerable attention to the accuracy of their entitlement computations and this facilitates the comparison with the discussion of the present section. They compare simulated and received benefits and observe that there is "considerable variation around the $45^{\circ}$ line. ${ }^{10}$ They note as one possible explanation the fact that the housing benefit is awarded for a period of 6 months. During such a period changes in entitlement might take place which lead to discrepancies between simulated and observed benefits. ${ }^{11}$ They also find that some of the people that are not entitled according to their simulation do nevertheless receive a subsidy, but typically a small amount. Their data seem to be much more favorable to the application cost hypothesis than ours. Information about refused applications was not used in their study, presumably because it was absent in the data. In the next section we will see how such information can influence the results of explanatory analyses.

A general discussion of the consequences of incomplete information about entitlement for the analysis of the take-up of means tested benefits is offered by Duclos (1995). $\mathrm{He}$ also takes into account the possibility that errors are made in refusing requests for means-tested benefits. His methodological framework implies that it is usually impossible to identify the take-up unless strong assumptions are made about the accurateness of the simulation and that of the decisions to grant applications. These assumptions can only be relaxed if more information than is usually available can be employed. As we will see below, WBO 98 offers some pieces of information that are not used in earlier studies.

\footnotetext{
${ }^{10}$ Page 63.

${ }^{11}$ Although the authors claim that in their figure 1, there is a slightly higher proportion of observations above the diagonal than below, my own 'eyeball' test (in which I cover the observations below or above the main diagonal in turn) suggests the contrary. For the majority of their observations, simulated benefits are larger than actual benefits, as found in the data used here.
} 


\section{A Modeling Limited Take-Up of the Housing Subsidy}

In this section we present the three empirical models that are used in this study. All three models consider the question of the take-up of the IHS conditional upon the housing consumption and the income of the household. ${ }^{12}$ Model I is a traditional formulation in which we simulate entitlement on the basis of WBO-information and analyze take-up within this group by means of a probit model. The other two models extend this framework by incorporating additional information into the analysis. In model II we use the information about refused applications for IHS contained in WBO. All households that rent a dwelling and do not receive IHS are asked whether they requested the benefit unsuccessfully. For all those receiving IHS we know that they requested the benefit. We have therefore information that informs us about the decisions the municipal authorities took, and can relate this to household characteristics and our simulated entitlement indicator. In model II we use two probit. One is essentially equal to that of model I and analyzes the decision to apply. It is now estimated on all renters. The other analyzes the decision whether or not to grant the benefit, when a households applies for it.

In model III we also address the problems associated with the income variable. We do so by introducing the distinction between IHS-income and WBO-income explicitly in our model. The WBO does not contain direct information about IHS income, but it was noted in section 2 that for those who receive IHS we can compute the IHSincome on the basis of the reported values of IHS, rent and household composition. In the remainder of this section we discuss the three models in greater detail.

Before doing so, we should mention that Koning and Ridder (1997) provide a structural model of renter's demand for housing in the presence of IHS on the basis of an earlier version of WBO. Their model incorporates the decision to take up the subsidy. Take-up is identified in their model essentially on the basis of the assumption that simulated entitlement equals actual entitlement and that all claims of entitled households will be granted. Non-take-up is explained by application costs and they estimate these costs to be quite high. The models developed in this paper are not concerned with housing demand, but focus on the decision to take-up the housing benefit, conditional upon the housing situation. In this respect they are more limited. However, the models of the present paper provide a more extensive analysis by incorporating a sub-model for the decision to grant the benefit once an household has applied for it (models II and III), and by taking into account explicitly the discrepancy between income as reported in WBO and income that was the basis for granting the benefit (model III).

\section{Model I}

Model I is estimated on all observations who receive IHS or are entitled to IHS according to our simulation, but do not receive it. It is a conventional probit model. In choosing our explanatory variables, we tried to focus on the take up of IHS among the groups that are presumably most in need of it. Accordingly, we incorporated dummies for households with WBO-incomes at or below the (group specific) minimum level as used in Dutch social security. Another explanatory variable is the value of the benefit. For households receiving the benefit this variable is set equal to the value reported in the WBO. For the others it is set equal to the simulated value. Although we know that

\footnotetext{
${ }^{12}$ See Koning and Ridder (1997) and Fischer (2000) for an analysis of the effects of a rental subsidy on housing consumption and labor supply, respectively.
} 
the actual values can differ substantially from the simulated values, this seemed to be the best way to proceed. The loglikelihood for an individual observation $i$ is equal to:

$$
\ell_{i}^{I}=d_{A}\left(1-\Phi\left(-X_{i}^{I} \beta\right)+\left(1-d_{A}\right) \Phi\left(-X_{i}^{I} \beta\right)\right.
$$

where $\ell$ denotes the loglikelihood, $d_{A}$ is a dummy denoting application of IHS, $X$ is a vector of explanatory variables, $\beta$ is a coefficient to be estimated and $\Phi$ is the cumulative standard normal distribution. The income variable used here to explain the decision to apply is WBO-income.

\section{Model II}

In model II we analyze the decision to apply for IHS independent of our simulation of entitlement. The model is therefore estimated on all observations of renting households. In this second model we take into account explicitly that the benefit will not be granted to all that apply for it. The decision (taken by a municipal authority) to grant an application is modeled by means of a second probit model. We use our simulated entitlement as an explanatory variable in both models. If the simulation were completely accurate, this second model would generate an infinitely large coefficient for the simulated entitlement dummy. The loglikelihood is in this case equal to:

$$
\begin{array}{r}
\ell_{i}^{I I}=d_{A} d_{G}\left(\left(1-\Phi\left(-X_{i}^{I I} \beta\right)\left(1-\Phi\left(-Z_{i}^{I I} \gamma\right)\right)\right)+\right. \\
d_{A}\left(1-d_{G}\right)\left(\left(1-\Phi\left(-X_{i}^{I I} \beta\right)\left(\Phi\left(-Z_{i}^{I I} \gamma\right)\right)\right)+\right. \\
\left(1-d_{A}\right) \Phi\left(-X_{i}^{I I} \beta\right) .
\end{array}
$$

In this equation $d_{G}$ is a dummy variable that is equal to 1 if the benefit is granted and equal to 0 otherwise, $Z$ denotes a second vector of explanatory variables (some or all of these may be equal to those in $X$ ) and $\gamma$ the associated vector of coefficients to be estimated.

\section{Model III}

Models I and II both use the assumption that the WBO-income can be used for studying the decision to apply for and to grant the IHS. In model III we take the alternative position that the IHS-income is the appropriate explanatory variable for both decisions. This immediately raises the problem that IHS-income is unknown for respondents who do not receive IHS.

In order to deal with this problem we assume that for all households in our sample there exists an IHS-income as well as the WBO-income that is reported. We denote the former income as $y^{\text {ihs }}$ and the latter as $y^{\text {wbo }}$. Let $f\left(y^{\text {ihs }}, y^{\text {wbo }} \mid x\right)$ denote the simultaneous distribution of the two incomes for households with characteristics $x$. For all respondents in the WBO we observe $y^{\text {wbo }}$. For those respondents who report to receive IHS, we can compute the value of $y$ ihs on the basis of the information they report about the amount of IHS received, rent and household characteristics. Our strategy will be to postulate a convenient specification for $f$ and estimate its parameters. The preferred specification should be easy to estimate and preferably flexible enough to give a reasonable description of the data. The bivariate lognormal distribution seems well suited for this purpose. Its marginal distributions are lognormal, and this is a standard specification for income distributions. The interaction between the two distributions can be described by a single variable, the 
correlation coefficient. It is possible to relate the parameters of the distribution to explanatory variables such as the group to which a household belongs, which introduces some flexibility.

One potential drawback of the lognormal is that it cannot deal with negative incomes. However, this is a minor problem. Entitlement for IHS does not change with income when it is lower than the social minimum. Moreover, in dual earner households where one of the partners has a negative income, the income that determines entitlement is that of the partner with the positive income only. ${ }^{13}$ Moreover, computation of the IHS-income (as discussed above) can only reveal that this income is at most equal to the social minimum, not that it is below zero.

We discuss the likelihood function of this model by focusing on the various configurations that have to be treated one by one. The easiest case is that in which a household has successfully applied for the benefit. We then extend the likelihood of model III with a term describing the likelihood of the particular combination if IHSand WBO-income:

$$
\ell_{i}^{I I I}=f\left(y_{i}^{i h s}, y_{i}^{w b o}\right)\left(1-\Phi\left(-X_{i}^{I I I} \beta\right)\left(1-\Phi\left(-Z_{i}^{I I I} \gamma\right)\right) \quad \text { if } \quad d_{A}=d_{G}=1\right.
$$

Note that in this case IHS-income is a component of the vectors $X$ and $Z$, whereas WBO-income is not. One difficulty associated with this equation is that we do not know the exact IHS-income, but only the interval to which it belongs. In all but one case this interval is small (see the discussion above) and we simply took its midpoint. The exceptional case occurs for low incomes, i.e. incomes below the social minimum. For this case we used the conditional distribution for the IHS-income at the known WBO-income. The likelihood function for this case is:

$$
\ell_{i}^{I I I}=\int_{0}^{y_{i}^{\min }} f\left(y^{i h s} \mid y_{i}^{w b o}\right) d y^{i h s}\left(1-\Phi\left(-X_{i}^{I I I} \beta\right)\left(1-\Phi\left(-Z_{i}^{I I I} \gamma\right)\right) \quad \text { if } \quad d_{A}=d_{G}=1\right.
$$

where $y^{\text {min }}$ denotes the social minimum income level. The terms referring to the two probit equations can be left out of the integration sign by virtue of the fact that the explanatory variables we use do not change with IHS-income as long as this income is below the social minimum. For instance, the normative rent is equal to Dfl 330,- per month for all incomes up to the social minimum level.

When a household does not receive the benefit, IHS-income is unknown. We will now assume that it is, nevertheless, a determinant of the decisions to apply for and to grant the subsidy. The probit equations describing these two decisions are therefore formulated conditional upon the value of the IHS-income and have to be integrated over the domain of the IHS income. For households that have unsuccessfully applied for the benefit, the likelihood becomes:

$$
\ell_{i}^{I I I}=\int f\left(y^{i h s} \mid y^{w b o}\right)\left(1-\Phi\left(-X_{i}^{I I I} \beta\right)\left(\Phi\left(-Z_{i}^{I I I} \gamma\right)\right) d y^{i h s} \quad \text { if } \quad d_{A}=1, d_{G}=0 .\right.
$$

\footnotetext{
${ }^{13}$ This has been taken into account in the incomes that were used for our simulations of entitlement for IHS. Among the more than 43.000 renting households 97 had a negative household income after this rule was applied. In estimating model III, these incomes have been set equal to 0 .
} 
Note that in this case the probit terms are placed under the integration sign in order to reflect the fact that explanatory variables such as the value of the benefit to which a household is entitled are now dependent upon IHS-income.

For households that did not apply, the likelihood is:

$$
\ell_{i}^{I I I}=\int f\left(y^{i h s} \mid y^{w b o}\right) \Phi\left(-X_{i}^{I I I} \beta\right) d y^{i h s} \quad \text { if } \quad d_{A}=0 .
$$

The integral in the likelihood in the latter two cases is approximated by simulation. In doing this, we make use of the fact that the conditional probability density function $f\left(y^{i h s} \mid y^{w b o}\right)$ is lognormal. We start by taking random drawings from the standard normal distribution and transform them to random drawings of $\ln \left(y^{\text {ihs }}\right)$ for the given value of $y^{w b o}$. Taking exponents leads to the implied values of $y^{i h s}$.

\section{Estimation results}

In this section we discuss estimation results for the three models. Descriptive statistics for the explanatory variables that have been used are given in Table 3 . The first row in the table refers to the dummy that indicates that a IHS-benefit is received. The next three lines to group dummies. The IHS-benefit if equal to the actual benefit for households that receive IHS and to the simulated benefit for households that do not receive it. The simulated value is equal to 0 for households that are not entitled according to our simulation, and do not receive the benefit. The next two rows refer to dummies for household that have an income at or below the level that is considered to be the minimum acceptable level in the Netherlands. ${ }^{14}$ Surplus income is defined as the difference between household income and the social minimum income level. The other variables do not require explanation except the last one. WBO 98 also contains direct information about (monthly) income fluctuations and the value of this variable indicates the value of such fluctuation.

Two samples are distinguished, one referring to model I, the other to model II. The sample used for estimating model III is the same as that for model II, except for the observations of households that receive IHS, but for which an IHS-income could not be computed. These households the reported combination of rent, IHS-benefit and household composition that should be impossible according to the IHS-rules. The sample used for estimating model I consists of households that receive IHS and households that are entitled to the benefit according to our simulation. The sample used for estimating model II contains all renting households. In this large sample the share of households that receive IHS is lower, the average value of the received or simulated benefit (the latter being equal to zero if a household is not entitled) is lower and incomes are on average higher.

\section{Model I}

The probit model that describes the decision to apply for those entitled to the benefit has significant positive coefficients for the dummy variables indicating that a household belongs to groups 1,3 or 4 . This implies that households belonging to group 2, the largest group on which earlier studies have focused, are the ones that are least inclined to claim the benefit (all else equal). The value of the benefit has a significant negative coefficient. This result is somewhat unexpected, as other studies have found a positive relation between the take-up rate and the value of the simulated

\footnotetext{
${ }^{14}$ All households are in principle able to reach this minimum income level by applying to social security benefits. A relatively large number of households nevertheless report a (much) lower income.
} 
benefits (see e.g. Blundell et al.; 1988, Daponte et al., 1998). However, the result is in line with the figures presented in Table 2.

The dummies for poor households (those with income at most equal to the social minimum of the group to which they belong) and single parent families are included because poverty policy is especially directed to these groups. The significant positive coefficients that we estimate suggest that non take-up of the benefit is considerably less of a problem for these two groups than for others. Since the households with the lowest incomes usually can claim a relatively high benefit, the incorporation of this variable may have contributed to the negative coefficient we found for the value of the benefit.

Surplus income has a significant positive coefficient, which is also unexpected. A possible explanation is that those with a higher income are better aware of the subsidy and more able to fill the forms et cetera.

Most of the rental housing in the Netherlands is owned by non-profit organizations who often provide help in applying for the housing benefit. Private landlords are less likely to do so. We therefore expect that their renters will less often claim the benefit and this expectation is confirmed by the negative coefficient that we estimate. Persons of a higher age may be less inclined to apply for the subsidy either for reasons associated with old age, or because of different sensitivity for stigma. We find the expected negative coefficient for age. Dual earners apply for the subsidy more often than would be expected on the basis of their other characteristics. The presence of children in the household may (all else equal, in particular income levels) indicate a higher need for benefits like the IHS. We estimate the expected positive coefficient. Self-employed persons may be less inclined to apply for the benefit because their incomes are more likely to fluctuate and incidental low incomes may not provide a strong incentive for applying for the benefit. We find the expected negative coefficient for this variable. Although we also find the expected negative coefficient for the variable that indicates income fluctuations, it is insignificant.

The estimation results of Model I may perhaps be interpreted as suggesting that ignorance and inability to make use of entitlement are important reasons for non-takeup. This ignorance and inability is concentrated among households with low incomes, a higher than average value of the benefit to which they are entitled and single earner households. The special attention that the government gives to households with income below the social minimum and to single parent households is reflected in a higher take-up of the benefit among these groups. The estimation results do not lend much support to the view that application costs are an important threshold for claiming the subsidy. Note, however, that this interpretation is based on the assumption that simulation error did not result in biased estimates for the coefficients.

\section{Model II}

Estimation results for model II confirm those for model I in some respects, but contradict them at a substantial number of other points. For the value of the benefit we now find a significant positive coefficient. For surplus income we now estimate significant negative coefficient. The results of the other variables that were also included in model I do not differ much. As an additional variable a dummy indicating that the household is entitled to a IHS-benefit according to our simulation is included in the model. It has a significant positive coefficient. It will be clear from this brief discussion that the estimation results for the decision to apply for the benefit in this second model are much more favorable to the application cost interpretation of limited take up than those of the first model. 
The second part of model II is the probit model that refers to the decision to grant an application for IHS is a new element of model II. We find positive coefficients for the three group dummies, indicating that households that do not belong to group 2 are more often granted the subsidy if they apply for it. Also in this model we find a highly significant positive coefficient for our entitlement dummy. If our simulations would have been completely accurate and municipal authorities would make no mistakes in granting the benefit, the coefficient for this variable should be infinitely large, and other variables could add nothing to the explanatory power of the model. Although actual estimation results do not approximate this situation, they indicate that our simulation, although imperfect, gives a useful approximation. Income receives a negative coefficient. This is possibly due to correlation between income and unobserved household wealth. Being self-employed or experiencing income fluctuations makes it also less likely that an application is granted. However, these coefficients are not significant.

\section{Model III}

Model III is based on the hypothesis that the actual decision-making process is based on the IHS-income and not on the WBO-income, i.e. the income reported in WBO 1998. We have accordingly only used the IHS-income in the estimation. One problem we had to face was that three variables (simulated value of the benefit, the dummy for having an income at or below the social minimum level and the dummy that indicates entitlement) are discontinuous functions of income. Since the values of the IHSincomes that we use in the estimation procedure are dependent upon the coefficients of the joint income distribution $f$ (see the previous section), this implied that the likelihood function is discontinuous in these parameters. We solved this problem by approximating the values of these variables by smooth functions. Details of the smoothing functions we use are given in the appendix. The approximations of the integrals in the likelihood function by means of simulation were based one 100 independent drawings from the standard normal distribution for each observation concerned.

Before estimating the model, we run some preliminary OLS regressions in order to get some idea about the relation between the two incomes. These regressions referred only to the 8,725 observations for which an IHS-income could be computed. If the computed IHS-income was equal to the minimum income level, we took $75 \%$ of that value in order to take into account that WBO-incomes are also often lower that the minimum income level. ${ }^{15}$ If the differences between the two incomes were small, one would expect an intercept close to 0 and a slope close to 1 . However, linear regression of the natural log of IHS-income on that of WBO-income resulted in a large intercept and a slope coefficient close to 0 . Moreover, the squared correlation coefficient was very low (0.05). These results did not change if we included dummies for three of the four groups. Although we should interpret these results with care, e.g. they refer to a truncated distribution ${ }^{16}$, they nevertheless suggest that we should not expect to find a very strong relation between the two incomes.

For 1,496 observations used in estimating model II the computed value of IHSincome resulted in a value below the social minimum income, sometimes negative. This implies that in a relatively large number of cases the assumptions on which our computation was based is incorrect. There must have been errors in the reported rent, benefit received or household composition (or in two or all these variables) for such

\footnotetext{
${ }^{15}$ Estimation results were not sensitive to this (arbitrary) decision.

${ }^{16}$ IHS-incomes can never be higher than the maximum value for which entitlement for IHS is possible.
} 
outcomes to be possible. This suggest that there may be substantial errors in the computation of IHS-income for the other observations as well. Despite this finding, we continued with the estimation of model III, while keeping it in mind when interpreting the estimation results.

Again we find that estimation results for some variables are markedly different when compared to those of the other two models. For the value of the benefit we now find a negative coefficient (as we did in model I, but unlike we did in model II), which is quite small. For the dummy indicating an income at or below the social minimum level we now find a large negative coefficient. For surplus income we find a large positive coefficient, which is nevertheless statistically insignificant. The dummy for entitlement now gets a much larger coefficient. Note, however, that also for this coefficient and for the coefficient referring to the minimum income we now find much larger standard errors that we did in model II.

Also in the part of the model referring to the decision to grant a subsidy, we find a much larger coefficient for the entitlement dummy. We also find a coefficient for surplus income that is much larger in absolute value, but has the wrong sign. Note again the much larger standard errors when compared with model II.

In the joint distribution of IHS and WBO-incomes we have allowed the $\mu$-parameters to be dependent on the group to which a household belongs. Estimation results confirm that single person households usually have lower incomes than the others and also show that elderly households with two or more persons often have somewhat lower incomes than non-elderly households with two or more persons that rent a house.

The $\sigma$-parameter is much larger for the WB-income than for the IHS-income. The correlation coefficient is negative, and close to zero (ene though it is statistically significant). In the light of our preliminary OLS-results this is not too surprising, but it implies that the WBO-income is almost useless for predicting IHS-income. The conditional distribution of IHS-incomes for an arbitrary WBO-income is almost the same as the unconditional distribution.

How should this finding be interpreted? If it would be taken literally in the context in which we developed the model, it implies that the income as reported in WBO provides no information about the income that is relevant for applying for the housing benefit. It means that the taxable household incomes that were relevant at the time when applying for IHS are independent from the taxable incomes that were relevant when the interview for WBO were taken. This is very hard to believe.

If one rejects this conclusion (and it seems that we have to do so), the assumptions on which model III was based must be wrong. Most probably the assumption that the correct IHS-income could be computed adequately from the information about rent, received housing benefit and household composition in the WBO-database is unwarranted. This confirms our earlier finding that in a relatively large number of cases the computation of HIS-income lead to results that did not make sense. It also explains the much larger standard errors that we find in model III for the explanatory variables that are related to IHS-income (value of the benefit, social minimum income, additional income, entitlement). Even though WBO-income is a poor indicator of the income that is relevant for granting or refusing the housing benefit, the computation of IHS-income does not succeed in improving upon it. This is somewhat disappointing since it suggests that the possibilities of making inferences about non-take up are limited by the quality of the data.

Two conclusions emerge. The first is that model II should be regarded as the preferred model. Model III demands too much from the data at hand. The second conclusion is 
that the values of rent, received housing benefit and possibly also household composition that are reported in WBO are (much) less precise than one would be inclined to think. Measurement error seems to be a much more important phenomenon than is often assumed.

\section{Conclusion}

In this paper we reconsidered the non-take-up of the Dutch housing benefit by being much more critical about the quality of the required simulation than earlier studies tended to be and by using additional information. It appears that a substantial part of the apparent non-take-up is due to simulation error. Simulation errors seems to be the most probable explanation of the frequently occurring substantial difference between simulated and reported benefits and of the substantial number of households that are not entitled according to the simulation, but nevertheless report to receive a benefit. The relatively large numbers of households that are apparently entitled to the benefit, but report that their application has been refused confirms this conclusion.

One might expect that simulation error will result in biased estimates of the explanatory variables for the non-take-up. If the sample on which the explanatory model is selected on the basis of erroneous simulations, this will in general effect the parameter estimates. Since our data allow us to model the decision to apply for a subsidy as well as the decision by the authorities to grant the subsidy, we were able to estimate a richer model of non-take-up than is conventionally used. Indeed, we found substantial differences in the signs and magnitudes of some estimated coefficients when we compared the extended model with a more traditional version. The model that incorporates the decision to grant a subsidy that has been applied for is much more in accordance with the application cost interpretation of non-take up than the first model.

Since our analysis identified the difference between the income that was relevant for applying for an IHS-benefit and the income reported in WBO as a critical variable in the simulation error, a third model was developed. The basic hypothesis of this model is that the income that is relevant for the decision-making process with respect to IHS (both for the decision to apply for and the decision to grant the subsidy) can be different from that reported in WBO. For the households that receive an IHS-benefit, the relevant IHS-income could be computed. For the others we had to proceed on the basis of the simultaneous distribution of the two incomes which we assumed to be equal for those that receive an IHS-benefit and those that do not. Estimation results of this third model were again different in some important respects from those of the other two. However, we had to conclude that the accuracy of the computed IHSincomes was much smaller than we supposed it to be. Since this implies that one of the important assumption on which the construction of the model is based is invalid, estimation results could not be interpreted.

A recurrent theme of the paper has been that the available data are easily interpreted to be more accurate than is actually warranted. We showed this to be the case for the taxable income as reported in WBO. Later on we had to conclude that the third model proposed in this paper had also demanded too much from the data. Since the WBO data have been gathered and edited carefully by Statistics Netherlands, so as to make them available for $\mathrm{m}$ (among other things) research such as reported in the present paper, it must be expected that the same phenomenon occurs in other research as well. 


\section{Literature}

Alessie, R., S. Hochguertel and A. van Soest (2001) Non-Take-up of Tax Favored Saving Plans, discussion paper 2001-122/3, Tinbergen Institute, Amsterdam.

Blundell, R., V. Fry and I. Walker (1988) Modelling the Take-Up of Means-Tested Benefits: The Case of Housing benefits in the United Kingdom Economic Journal 98 58-74.

Conijn, J.B.S. and W.C. Lamain (1992) Huursombeleid en de Gevolgen voor de Individuele Huursubsidie Ministerie van VROM

Daponte, B.O., S. Sanders and L. Taylor (1998) Why do Low-Income Households Not Use Food Stamps? Journal of Human Resources 34 612-628.

Duclos, J.-Y. (1995) Modelling the Take-Up of State Support Journal of Public Economics 58 391-415.

Fischer, W. (2000) Labor Supply Effects of Federal Rent Subsidies Journal of Housing Economics 9 150-174.

Gibson, C. (2001) Priveleging the Participant: The Importance of Take-Up Rates in Social Welfare Evaluations, working paper, Princeton University.

Koning, R. and G. Ridder (1997) Rent Assistance and Housing Demand Journal of Public Economics 66 1-33.

Moffit, R. (1983) An Economic Model of Welfare Stigma American Economic Review 73 1023-1035.

Oorschot, W.J.H. van (1994) Take It or Leave It, $\mathrm{PhD}$ thesis, KUB.

Rouwendal, J. (2000) Inkomensdynamiek en Onderbenutting van de Individuele Huursubsidie Kwantitatieve Methoden 21 no. 63, 49-73.

Vrooman, J.C. and K.T.M. Asselberghs (1994) De Gemiste Bescherming SCP.

Wildeboer Schut, J.M. (1997) Niet-gebruik van Huursubsidie, in: Armoedemonitor $1997 \mathrm{CBS} / \mathrm{SCP}$. 


\section{Appendix Smoothing some of the explanatory variables}

In section 2 the normative rent was discussed. Although it is a step function of income according to the tables used for granting or refusing applications for IHS, it is basically a quadratic function of income. The share of the normative rent in household income is a linear function of household income, as discussed in section 2. We used this (smooth) linear function in our computations of the normative rent. The parameters were determined on the basis of the tables just mentioned by a process of trial and error. At the midpoints of the income classes used in these tables the absolute difference between actual and computed normative monthly rent was usually less than Dfl 1.-.

If income exceeds a threshold value, no subsidy can be claimed and the normative rent is no longer defined. This introduces a discontinuity in the subsidy that can be claimed. In order to avoid it, we have ignored the threshold value of income when computing the normative rent, but we multiplied the subsidy with the smoothed variable that indicates entitlement.

Entitlement to a positive IHS-benefit is determined by two conditions: the rent should exceed the normative rent and income should be below the threshold value. (Both are group specific). We have smoothed this $0-1$ variable by means of the following formula:

$$
\phi\left(\frac{r-n h}{s_{1}}\right) \phi\left(\frac{y^{r}-y^{w b o}}{s_{2}}\right)
$$

In this expression $\phi$ denotes the density function of the standard normal distribution, $r$ is the actual rent, $n h$ the normative rent, $y^{w b o}$ income reported in WBO and $y^{r}$ threshold income, $s_{1}$ and $s_{2}$ are auxiliary parameters. If the values of $s_{1}$ and $s_{2}$ are small, this expression approaches the value of the dummy variable. It can therefore be regarded as a smoothed version of that variable. In our estimation we choos $s_{1}$ equal to 50 and $s_{2}$ equal to 500 .

Finally, we have the dummy variable that indicates that income is at or below the social minimum level. Instead of this variable we used:

$$
\phi\left(\frac{y^{s o c \min }-y^{w b o}}{s_{2}}\right)
$$

with the same value for $s_{2}$. 
Table 1 The take-up of the housing benefit (IHS)

\begin{tabular}{|c|c|c|c|c|c|}
\hline & & Group 1 & Group 2 & Group 3 & Group 4 \\
\hline & & $\begin{array}{l}\text { One person } \\
\text { households }\end{array}$ & $\begin{array}{l}\text { Households } \\
\text { with } 2 \text { or } \\
\text { more persons }\end{array}$ & $\begin{array}{l}\text { Elderly one } \\
\text { person } \\
\text { households }\end{array}$ & $\begin{array}{l}\text { Elderly } \\
\text { households } \\
\text { with } 2 \text { or } \\
\text { more persons }\end{array}$ \\
\hline 1 & Total number & 6090 & 20250 & 4227 & 6051 \\
\hline 2 & $\begin{array}{l}\text { Moved in } 97 \\
\text { or } 98\end{array}$ & 1361 & 2976 & 262 & 395 \\
\hline 3 & Entitled & 1542 & 4413 & 2616 & 2649 \\
\hline 4 & Not receiving & 613 & 2433 & 998 & 1363 \\
\hline 5 & $\begin{array}{l}\text { Amount } \\
\text { missed }\end{array}$ & 208.90 & 250.08 & 212.82 & 213.29 \\
\hline 6 & $\begin{array}{l}\text { Application } \\
\text { under } \\
\text { consideration }\end{array}$ & 45 & 89 & 39 & 36 \\
\hline 7 & $\begin{array}{l}\text { Application } \\
\text { refused }\end{array}$ & 142 & 454 & 239 & 306 \\
\hline 8 & Receiving & 929 & 1980 & 1618 & 1286 \\
\hline 9 & Amount & 225.72 & 279.37 & 233.69 & 209.24 \\
\hline 10 & $\begin{array}{l}\text { More than } 5 \% \\
\text { too much }\end{array}$ & 212 & 430 & 337 & 274 \\
\hline 11 & Amount & 90.41 & 108.21 & 88.13 & 86.10 \\
\hline 12 & $\begin{array}{l}\text { Too much, } \\
\text { but less than } \\
5 \%\end{array}$ & 91 & 203 & 118 & 77 \\
\hline 13 & Amount & 5.62 & 6.79 & 6.53 & 6.61 \\
\hline 13 & $\begin{array}{l}\text { Less than } \\
\text { simulated, but } \\
\text { less than } 5 \%\end{array}$ & 124 & 222 & 182 & 89 \\
\hline 14 & Amount & -6.82 & -7.96 & -8.26 & -8.89 \\
\hline 15 & $\begin{array}{l}\text { Less than } \\
\text { simulated, } \\
\text { difference } \\
\text { more than 5\% }\end{array}$ & 502 & 1125 & 981 & 846 \\
\hline 16 & Amount & -78.08 & -101.88 & -94.29 & -114.31 \\
\hline 17 & Not entitled & 3187 & 12861 & 1349 & 3007 \\
\hline 18 & Not receiving & 2873 & 12106 & 1180 & 2665 \\
\hline 19 & $\begin{array}{l}\text { Request } \\
\text { refused }\end{array}$ & 434 & 1360 & 162 & 333 \\
\hline 20 & Receiving & 314 & 755 & 169 & 342 \\
\hline 21 & Amount & 190.85 & 227.05 & 218.71 & 202.48 \\
\hline
\end{tabular}


Table 2 Take-up rates and value of the benefit

\begin{tabular}{cllllllll}
\hline & $\begin{array}{l}\text { Take-up } \\
\text { rate }\end{array}$ & $\mathrm{N}$ & $\begin{array}{l}\text { Take-up } \\
\text { rate }\end{array}$ & $\mathrm{N}$ & $\begin{array}{l}\text { Take-up } \\
\text { rate }\end{array}$ & $\mathrm{N}$ & $\begin{array}{l}\text { Take-up } \\
\text { rate }\end{array}$ & $\mathrm{n}$ \\
\hline $0-100$ & .72 & 619 & .66 & 1358 & .59 & 549 & .60 & 797 \\
$100-200$ & .71 & 621 & .66 & 1359 & .59 & 546 & .60 & 795 \\
$200-300$ & .72 & 343 & .48 & 932 & .68 & 642 & .58 & 667 \\
$300-400$ & .70 & 326 & .58 & 967 & .73 & 626 & .60 & 490 \\
$400-500$ & .64 & 163 & .57 & 729 & .71 & 393 & .58 & 318 \\
$500-600$ & .48 & 23 & .51 & 268 & & & .45 & 58 \\
$600-700$ & & & .50 & 12 & & & & \\
\hline
\end{tabular}


Table 3 Descriptive statistics

\begin{tabular}{lcccc}
\hline & \multicolumn{2}{c}{ Model I } & \multicolumn{2}{c}{ Model II } \\
\hline Variable & Mean & St. dev. & & \\
\hline Receives IHS & 0.5872 & & 0.2361 & \\
Group 1 & 0.1438 & & 0.1485 & \\
Group 3 & 0.2181 & & 0.1249 & \\
Group 4 & 0.2347 & & 0.1791 & \\
Amount of benefit & 185.99 & 116.02 & 74.80 & 137.31 \\
Minimum income & 0.5367 & & 0.2334 & \\
Single parent & 0.0598 & & 0.0495 & \\
Surplus income (x 1000) & 5.51 & 26.98 & 27.81 & 28.24 \\
Renting from private person & 0.0750 & & 0.1103 & \\
Age & 58.397 & 17.26 & 53.13 & 28.86 \\
Dual earners & 0.2971 & & 0.4480 & \\
Number of children & 0.5111 & 0.9318 & 0.5864 & 0.9279 \\
Self-employed & 0.0462 & & 0.0500 & \\
Income fluctuations & 0.1727 & 0.8763 & 0.2936 & 1.322 \\
& & & 0.3517 & \\
& & & 0.1095 & \\
\hline
\end{tabular}


Table 4 Estimation results

\begin{tabular}{|c|c|c|c|c|c|c|}
\hline \multirow{2}{*}{ Application } & \multicolumn{2}{|l|}{ Model I } & \multicolumn{2}{|l|}{ Model II } & \multicolumn{2}{|l|}{ Model III } \\
\hline & & & & & & \\
\hline Constant & 0.4005 & $(0.078)$ & -1.0217 & $(0.045)$ & -1.1842 & $(0.22)$ \\
\hline Group 1 & 0.6389 & $(0.046)$ & 0.5121 & $(0.029)$ & 0.2318 & $(0.044)$ \\
\hline Group 3 & 0.7930 & $(0.053)$ & 0.5859 & $(0.037)$ & 0.6475 & $(0.049)$ \\
\hline Group 4 & 0.2987 & $(0.049)$ & 0.2619 & $(0.031)$ & 0.2744 & $(0.041)$ \\
\hline $\begin{array}{l}\text { Value of the benefit } \\
(\mathrm{x} 100)\end{array}$ & -0.3894 & $(0.013)$ & 0.05072 & $(0.0090)$ & -0.07547 & $(0.085)$ \\
\hline Social minimal income & 0.7293 & $(0.033)$ & 0.1174 & $(0.026)$ & -1.5666 & $(0.19)$ \\
\hline Single parent & 0.6911 & $(0.050)$ & 0.5289 & $(0.039)$ & 0.4113 & $(0.053)$ \\
\hline $\begin{array}{l}\text { Surplus income } \\
\text { (x 1000) }\end{array}$ & 0.053069 & $(0.0037$ & -0.001158 & $(0.0002)$ & 2.587 & $(1.34)$ \\
\hline Private owner & -0.5296 & $(0.045)$ & -0.5043 & $(0.028)$ & -0.4302 & $(0.035)$ \\
\hline Age (x 10) & -0.08142 & $(0.013)$ & -0.01067 & $(0.0080)$ & -0.03339 & $(0.0096)$ \\
\hline Dual earners & 0.1926 & $(0.040)$ & 0.1155 & $(0.022)$ & -0.06391 & $(0.026)$ \\
\hline Number of children & 0.09223 & $(0.018)$ & 0.08877 & $(0.010)$ & 0.1068 & $(0.012)$ \\
\hline Self-employed & -0.6894 & $(0.075)$ & -0.3772 & $(0.040)$ & -0.1816 & $(0.053)$ \\
\hline Income fluctuations & -0.02635 & $(0.018)$ & -0.00347 & $(0.0076)$ & -0.004637 & $(0.0091)$ \\
\hline Entitlement & & & 0.9245 & $(0.025)$ & 1.724 & $(0.11)$ \\
\hline \multicolumn{7}{|l|}{ Grant } \\
\hline Constant & & & -0.2777 & $(0.030$ & -3.696 & $(0.32)$ \\
\hline Group 1 & & & 0.1816 & $(0.040)$ & -0.1988 & $(0.078)$ \\
\hline Group 3 & & & 0.2858 & $(0.040)$ & 1.035 & $(0.060)$ \\
\hline Group 4 & & & 0.1241 & $(0.036)$ & 0.3188 & $(0.062)$ \\
\hline Entitlement & & & 1.130 & $(0.029)$ & 2.821 & $(0.32)$ \\
\hline $\begin{array}{l}\text { Surplus income } \\
(\mathrm{x} 1000)\end{array}$ & & & -0.000797 & $(0.0003)$ & 6.342 & $(1.16)$ \\
\hline Self-employed & & & -0.09833 & $(0.075)$ & -0.1674 & $(0.14)$ \\
\hline Income fluctuations & & & -0.01819 & $(0.014)$ & -0.05327 & $(0.024)$ \\
\hline Income distribution & \multicolumn{6}{|c|}{$($ suffix $1=W B O$ income, suffix $2=I H S$-income $)$} \\
\hline$\mu_{1}$ & & & & & 10.47 & $(0.014)$ \\
\hline Group 1 & & & & & -0.3896 & $(0.017)$ \\
\hline Group 3 & & & & & -0.4779 & $(0.047)$ \\
\hline Group 4 & & & & & 0.09883 & $(0.038)$ \\
\hline$\sigma_{1}$ & & & & & 0.6047 & $(0.0010)$ \\
\hline$\mu_{2}$ & & & & & 10.28 & $(0.0028)$ \\
\hline Group 1 & & & & & -0.2458 & $(0.0046)$ \\
\hline Group 3 & & & & & -0.3022 & $(0.0050)$ \\
\hline Group 4 & & & & & -0.07365 & (0.0041) \\
\hline$\sigma_{2}$ & & & & & 0.1618 & $(0.0003)$ \\
\hline$\rho$ & & & & & -0.01425 & $(0.0029)$ \\
\hline Loglikelihood & $-7,107$ & & $-22,168$ & & $-134,486$ & \\
\hline $\mathrm{N}$ & 12,591 & & 31,305 & & 29,809 & \\
\hline
\end{tabular}

